\title{
Malignant vascular tumours of the pleura in "asbestos" workers and endothelial differentiation in malignant mesothelioma
}

\author{
R L Attanoos, S K Suvarna, E Rhead, M Stephens, T J Locke, M N Sheppard, \\ F D Pooley, A R Gibbs
}

Department of

Histopathology,

Llandough Hospital,

Cardiff, UK

R L Attanoos

A R Gibbs

Department of

Histopathology,

Northern General

Hospital, Sheffield, UK

S K Suvarna

Department of

Histopathology, North

Staffordshire General

Hospital, Stoke on

Trent, UK

E Rhead

M Stephens

Department of

Histopathology, Royal

Brompton Hospital,

London, UK

M N Sheppard

Department of

Surgery, Northern

General Hospital,

Sheffield, UK

T J Locke

Division of Materials and Minerals,

University of Wales, Cardiff, UK

F D Pooley

Correspondence to:

Dr R L Attanoos,

Department of

Histopathology, Llandough

Hospital, Cardiff CF64 2XX,

UK

Received 11 November 1999

Returned to authors

20 March 2000

Revised version received

11 July 2000

Accepted for publication

12 July 2000

\begin{abstract}
Background-Three cases of diffuse malignant vascular tumours of the pleura are described which mimicked malignant mesothelioma clinically and pathologically (so called "pseudomesothelioma"). All had occupational histories of exposure to asbestos. The relationship of these tumours to mesothelioma and asbestos exposure is discussed.
\end{abstract}

Methods-To examine the histogenetic relationship between mesothelioma and these three tumours an immunohistochemical analysis of vascular marker (CD31, CD34, and Von Willebrand factor) expression was undertaken in 92 cases of pleural mesothelioma, in addition to these three tumours. Electron microscopic fibre analysis of lung tissue was performed on each of the three cases to assess asbestos fibre content.

Results-Diffuse pleural epithelioid haemangioendotheliomas may closely resemble malignant mesothelioma clinically and pathologically but, of the 92 pleural mesotheliomas tested, none showed expression of CD31, CD34, and Von Willebrand factor. Although all three cases had claimed exposure to asbestos, ferruginous bodies typical of asbestos were only seen by light microscopy in case 2 , and only in this subject was the asbestos fibre content raised in comparison with the range seen in a non-exposed background population. The latent period in the pleural epithelioid haemangioendotheliomas ranged from 18 to 60 years.

Conclusions-Endothelial differentiation does not appear to occur in mesothelioma and therefore should be clearly separated from it. No definite association between pleural epithelioid haemangioendothelioma and exposure to asbestos can be made from this small series but further investigation is warranted.

(Thorax 2000;55:860-863)

Keywords: pleura; epithelioid haemangioendothelioma; asbestos; mesothelioma

There are well established associations between exposure to asbestos and several pleural conditions including hyaline plaques, diffuse fibrosis, and malignant mesothelioma $\mathrm{m}^{1-3}$ but no association with vascular tumours of the pleura has been made. In this report three cases of primary pleural epithelioid haemangioendothelioma are described which have occurred in subjects with a history of occupational exposure to asbestos who have had a full electron microscopic fibre analysis of lung tissues. The differential diagnosis between these tumours and malignant mesothelioma is discussed particularly with regard to their immunohistochemical profiles. The medicolegal implications of the diagnosis of pleural epithelioid haemangioendothelioma are considered.

\section{Case reports}

The three cases presented were each referred for pathological review during the process of medicolegal compensation claims for asbestos related disease. The clinical data and necroscopic information from the three patients with primary pleural epithelioid haemangioendothelioma are shown in table 1 . The occupational asbestos exposure is given in table 2 . Necroscopic examination showed that the pleura was the sole or major site of disease. The pathological diagnosis was independently made by at least two experienced pulmonary histopathologists after consideration of haematoxylin and eosin stained slides and a wide panel of immunohistochemical markers. In all cases ultrastructural studies were performed.

Table 1 Clinical features of primary pleural angiosarcomas (epithelioid haemangioendothelioma)

\begin{tabular}{|c|c|c|c|c|c|c|}
\hline Case & Sex & Age (years) & Clinical & Radiology & $\begin{array}{l}\text { Course } \\
\text { (months) }\end{array}$ & Necroscopic findings \\
\hline 1 & $M$ & 59 & $\begin{array}{l}\text { Pleuritic pain, } \\
\text { dyspnoea }\end{array}$ & $\begin{array}{l}\text { Effusion, diffuse } \\
\text { pleural thickening, } \\
\text { plaques (CXR, CT) }\end{array}$ & 7 & $\begin{array}{l}\text { Diffuse pleural tumour, } \\
\text { hyaline pleural plaques, } \\
\text { ferruginous bodies in lung }\end{array}$ \\
\hline 2 & M & 73 & $\begin{array}{l}\text { Chest infection, } \\
\text { dyspnoea }\end{array}$ & $\begin{array}{l}\text { Effusion, pleural } \\
\text { fibrosis,pleural mass, } \\
\text { plaque (CXR,CT) }\end{array}$ & 9 & $\begin{array}{l}\text { Diffuse pleural tumour, } \\
\text { pleural fibrosis, classical } \\
\text { asbestos bodies in lung }\end{array}$ \\
\hline 3 & $M$ & 33 & $\begin{array}{l}\text { Cough, pleuritic } \\
\text { pain, dyspnoea }\end{array}$ & $\begin{array}{l}\text { Effusion, parietal } \\
\text { pleural thickening, } \\
\text { diaphragm and } \\
\text { pericardial spread } \\
(\mathrm{CXR}, \mathrm{CT})\end{array}$ & 8 & $\begin{array}{l}\text { Diffuse pleural neoplasm } \\
\text { with local invasion of } \\
\text { mediastinum and } \\
\text { diaphragm. Contralateral } \\
\text { plaque. Ferruginous bodies, } \\
\text { many coarse "welding type" }\end{array}$ \\
\hline
\end{tabular}


Table 2 Occupational details, tumour latency and cumulative asbestos exposure

\begin{tabular}{lllll}
\hline Case & Occupation & $\begin{array}{l}\text { First exposure and } \\
\text { duration }\end{array}$ & $\begin{array}{l}\text { Latency } \\
\text { (years) }\end{array}$ & Intensity \\
\hline 1 & Labourer & $1956-8$ (2 years) & 42 & $\begin{array}{l}\text { Light, unknown } \\
\text { frequency }\end{array}$ \\
2 & Shipyard joiner & $1938-43(5$ years & 60 & $\begin{array}{l}\text { Heavy, intermittent } \\
\text { Heavy, intermittent }\end{array}$ \\
\hline
\end{tabular}

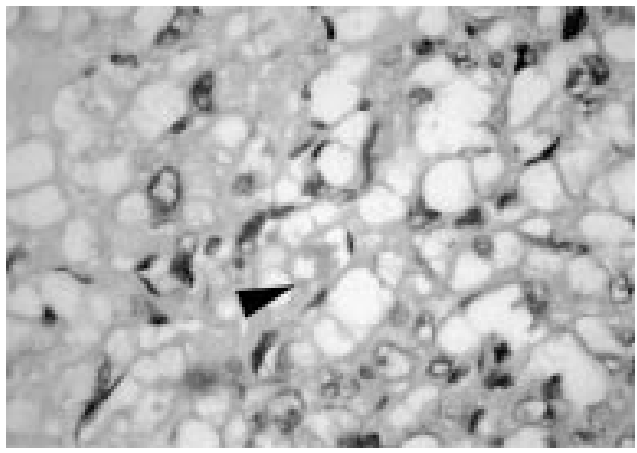

Figure 1 Epithelioid haemangioendothelioma with spindle and vacuolated cell forms showing neovascular lumina with erythrocytes (arrow). Stain: $H \in \mathcal{E} E, \times 400$ magnification.

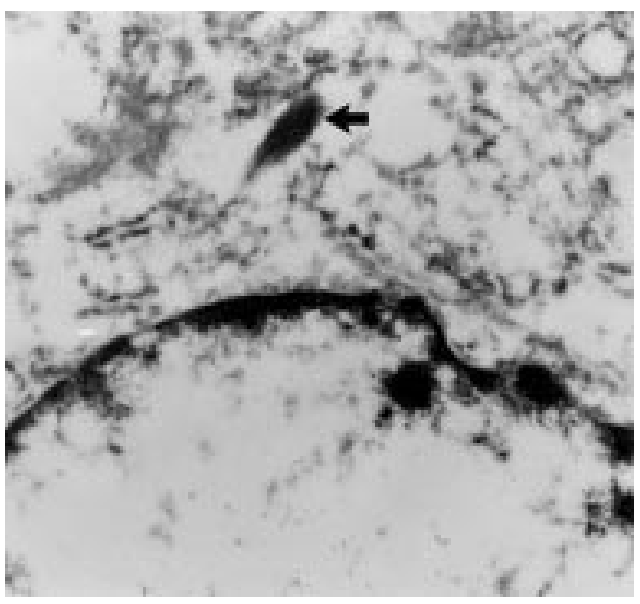

Figure 2 Epithelioid haemangioendothelioma (case 1) containing intracytoplasmic Weibal-Palade organelle (arrow). EM, $\times 57000$ magnification.

In each case the parietal pleura was diffusely replaced by tumour composed of epithelioid and vacuolated cells forming small nests and cords with a minor spindle cell component. The tumour cells showed a moderate degree of cytonuclear pleomorphism and intracellular neovascular lumina containing erythrocytes were present (fig 1). Immunohistochemistry revealed that the tumour cells were positive for vimentin and with at least two of the three endothelial markers (CD 31, CD34, von Willebrand factor). In case 3 this additionally included the vascular marker thrombomodulin. The identification of intracytoplasmic Weibal-Palade organelles confirmed en-

Table 3 Electron microscopic mineral analysis on lung tissue (fibres/g dry lung tissue $\times$ $10^{6}$ )

\begin{tabular}{lllllll}
\hline Case & Total & Amosite & Crocidolite & Chrysotile & Mullite & Others \\
\hline 1 & 27.2 & ND & ND & ND & 8.8 & $\begin{array}{l}18.4(0.5 \\
\text { tremolite })\end{array}$ \\
2 & 51.7 & \multirow{2}{*}{12.3} & 29.5 & ND & 7.5 & 2.4 \\
3 & 6.9 & 0.4 & ND & 0.2 & 5.8 & 0.5 \\
\hline
\end{tabular}

In case 1 non-fibrous mineral analysis revealed that $90 \%$ of particulate matter was mica. $\mathrm{ND}=$ not detected. dothelial differentiation in cases 1 and 2 (fig 2). The diagnosis in both cases was of primary pleural epithelioid heamangioendothelioma. In case 3 the tissue was suboptimal for ultrastructural analysis. Four independent pathological opinions were sought and the overall favoured diagnosis was of primary pleural angiosarcoma (epithelioid heamangioendothelioma).

\section{Methods}

Mineral fibre analysis was undertaken on representative lung tissue blocks. Lung tissue samples were digested in $40 \%$ potassium hydroxide, washed, and ashed at $350^{\circ} \mathrm{C}$ in oxygen. The abstract was suspended in distilled water and aliquots were filtered on nucleopore filters. These were then carbon coated and the filters dissolved in chloroform. The carbon films were mounted onto gold electron microscope support grids for transmission electron microscopy. Fibres were counted and typed by an energy dispersive $x$ ray analysis technique. ${ }^{4}$

The potential role of immunohistochemistry in the diagnosis and distinction of malignant vascular tumours of the pleura from malignant mesothelioma prompted an analysis of endothelial marker expression in malignant mesothelioma. Paraffin embedded blocks from 92 cases of malignant mesothelioma (84 Llandough Hospital, Penarth/8 Northern General, Sheffield) were retrieved from the files. Standard sections were cut and stained with haematoxylin and eosin for morphological assessment. Each case was chosen on account of its typical light microscopic appearance for malignant mesothelioma and supportive immunophenotype by use of a broad antibody panel.

An immunohistochemical study was performed using an avidin/biotin/peroxidase complex (ABC method) with antibodies to von Willebrand factor (Dako, 1 in 200 dilution), CD34 (Europath, 1 in 200 dilution), and CD31 (Dako, 1 in 20 dilution). Suitable positive and negative control tissues were included.

\section{Results}

The results of the mineral analysis are shown in table 3. The putative latent periods of the three cases ranged from 18 to 60 years, with cumulative exposures to asbestos of 2-17 years. In cases 1 and 3 the intensity of asbestos exposure was light. In both cases ferruginous bodies were present but they were typical of asbestos only in case 2 . In this case there was intermittent heavy exposure to asbestos and lung fibre burdens reflect the occupational history. Cases 1 and 3 do not show a clear cut increase in asbestos fibre levels.

The results of the immunohistochemical study of vascular marker expression in malignant mesothelioma shows that there was no immunoreactivity for CD31, CD34, or von Willebrand factor in any of the subtypes of the 92 malignant mesotheliomas tested.

\section{Discussion}

Epithelioid haemangioendothelioma is an uncommon low grade sarcoma of endothelial origin recognised in a variety of tissue sites 
including liver, soft tissue, lung, bone, and skin. ${ }^{5}$ It has been described as originating from the pleura ${ }^{6}$ and peritoneum. ${ }^{7}$

In the pleura the main differential diagnosis is that of diffuse malignant mesothelioma ${ }^{8}$ and clinicopathological distinction can be problematical. Firstly, a diffuse serosal growth pattern is a characteristic feature of malignant mesothelioma but this "mesotheliomatous" pattern is not specific and has been recognised in some non-mesothelial tumours, most notably carcinomas and, very rarely, sarcomas including epithelioid haemangioendothelioma. Secondly, on morphological grounds, epithelioid haemangioendothelioma may exhibit a biphasic pattern with epithelioid and spindle areas similar to biphasic malignant mesothelioma.

The accurate distinction of the two tumours has important medicolegal implications as only malignant mesothelioma is currently recognised as an asbestos related neoplasm for compensation purposes. The description of three primary pleural angiosarcomas in individuals exposed to asbestos raises two important questions. Firstly, do mesotheliomas have the capacity to undergo vascular differentiation and, secondly, if not, are pleural angiosarcomas aetiologically linked with asbestos?

Divergent differentiation of mesothelium has been described and cases of malignant mesothelioma showing leiomyoid, chondroid, osseous, and liposarcomatous patterns have been reported. ${ }^{9}$ Bona fide cases of malignant mesothelioma showing angiosarcomatous differentiation have not been described.

In order to address the issue of vascular differentiation in malignant mesothelioma an immunohistochemical analysis of 92 mesothelioma was undertaken using the three most sensitive and specific vascular markers (CD $31,{ }^{10}$ CD $34,{ }^{11}$ and von Willebrand factor $\left.^{12}\right)$. In one recent study two of 16 malignant mesotheliomas and five of 84 mixed carcinomas showed weak non-specific cytoplasmic CD31 staining. ${ }^{13}$ In a further series ${ }^{14}$ no CD31 expression was seen in any of nine malignant mesotheliomas tested. The expression of von Willebrand factor and CD34 has not been reported in malignant mesothelioma and the results of this study support previous investigations. ${ }^{8}$ The present study indicates no definite immunohistochemical evidence of vascular differentiation in any of the cohort of 92 malignant mesotheliomas studied and we conclude that vascular marker expression (and endothelial differentiation) does not occur or is a very infrequent finding in malignant mesothelioma. The use of a combination of the vascular markers CD31 and CD34 would therefore allow effective distinction of malignant mesothelioma from epithelioid angiosarcoma.

Considering the aetiological role of asbestos, in the largest published series of 14 malignant vascular tumours involving the serous membranes $^{8}$ only one case of epithelioid angiosarcoma had a prior history of asbestos exposure. In order to ascribe mesothelioma to exposure to asbestos certain conditions must be met including (1) accurate diagnosis, (2) reliable evidence of exposure to amphibole asbestos, (3) an appropriate latent period, and (4) an absence of confounding aetiological factors such as irradiation or erionite mineral fibre exposure.

The diagnosis of these three cases has been discussed. The evidence of asbestos exposure can come from various sources including occupational history, light microscopic identification of asbestos bodies in lung tissue sections, and mineral fibre analysis of tissue digests. The reliability of occupational history is strongly dependent on "recall" which varies between occupations and is subject to bias whereby individuals can underestimate or overestimate their exposure to asbestos. Electron microscopic mineral fibre analysis allows for the accurate determination of asbestos fibre burden and fibre type at death. For case 2 all parameters indicated an increased crocidolite asbestos fibre count consistent with an occupational exposure. However, for cases 1 and 3 the mineralogical results were equivocal. Case 1 worked most of his life as an underground coal miner but for a period of about two years (prior to mining) worked as a labourer demolishing sheds said to contain asbestos roofing materials. Light microscopy showed occasional ferruginous bodies but no "classical" asbestos bodies. Mineral fibre analysis showed a low level of tremolite, a contaminant amphibole of chrysotile (white) asbestos ore. It is possible that the major asbestos exposure in this case was to chrysotile. However, it is well known that the biopersistence of chrysotile is low and, with clearance over a 32 year period, the fibre may have been undetectable by mineral analysis at death. A further interesting finding in this case was that $90 \%$ of the non-fibrous particulate matter was mica. The mica consisted of very large plates and was not typical of that usually seen in association with coal mining. Mica has been associated with ferruginous body formation (which are sometimes mistaken for "classical" asbestos bodies) and pleural plaques, ${ }^{15}$ and an awareness of this is important to prevent a false attribution to asbestos, particularly in the presence of a diffuse pleural tumour. There is no known association of mica with malignant mesothelioma. In summary, only the occupational history indicated exposure to asbestos. In case 3 there was a positive occupational history of exposure to asbestos as a shipyard welder but the chrysotile and amosite asbestos fibre levels detected were not clearly elevated above those identified in the background control population. Many ferruginous bodies and iron coated platy material were present, as frequently occurs in welders. ${ }^{16}$

An appropriate latent period (from initial exposure to asbestos to death of the patient) is an important factor in the ascription of an asbestos induced neoplasm. In a study of 1690 cases of malignant mesotheliomas the latent period was in excess of 15 years in $99 \%$ of cases. ${ }^{17}$ In comparison, in a series of occupational related (hepatic) angiosarcomas following exposure to vinyl chloride monomer ${ }^{18}$ the latent period was 8-32 years with a mean latency in excess of 20 years. In this series of pleural epithelioid haemangioendothelioma 
the tumour latency period was similar to that seen in asbestos related malignant mesotheliomas and ranged from 18 to 60 years. It is of course recognised that, whilst the pathogenic mechanisms of vinyl chloride and asbestos in neoplastic transformation may be considerably different, the studies do highlight the fact that long latent periods exist between initial exposure to the carcinogen and death of the patient in the two tumour sites (liver and pleura).

With respect to confounding factors, hepatic angiosarcomas have been aetiologically associated with radiotherapy, anabolic steroids, vinyl chloride monomer, and thorotrast. None of the patients in this series was known to have any of these risk factors. Because of their rarity, no risk factors for pleural angiosarcomas have been clearly defined.

In summary, three cases of primary epithelioid haemangioendothelioma of the pleura in patients who claimed prior exposure to asbestos are presented. The results of the immunohistochemical study do not support the view that endothelial differentiation occurs in malignant mesotheliomas. We advocate the introduction of endothelial markers such as CD31 and CD34 into the routine immunohistochemical panel used in the identification of malignant mesothelioma so that effective distinction from epithelioid haemangioendothelioma can be made. With regard to the aetiology (that is, asbestos), it is recognised that the three cases were identified during pursuit of medicolegal compensation claims for asbestos related disease and therefore demonstrate referral bias. However, further multicentre case-control studies with mineral fibre analysis should be prompted by the findings of this series to determine whether there is a genuine and consistent association between epithelioid haemangioendothelioma and exposure to as- bestos and, if so, to determine whether there are similar dose responses and latency periods as in malignant mesothelioma.

1 Churg A. Asbestos fibres and pleural plaques in a general autopsy population. Am F Pathol 1982;109:88-96.

2 Stephens M, Gibbs AR, Pooley FD, et al. Asbestos induced diffuse pleural fibrosis: pathology and mineralogy. Thorax 1987;42:583-8.

3 Wagner JC, Sleggs CA, Marchand P. Diffuse pleural mesotheliomas and asbestos exposure in a north western Cape Province. Br f Ind Med 1960;17:260-71.

4 Pooley FD, Ransome DL. Comparison of the results of asbestos fibre dust counts in lung tissue obtained by analytical electron microscopy and light microscopy. $\mathcal{F}$ Clin analytical electron mic

5 Weiss SW, Ishak KG, Dail DH, et al. Epithelioid haemangioendothelioma and related lesions. Semin Diagn Pathol 1985;3:270-80.

6 Yousem SA, Hochholzer L. Unusual thoracic manifestations of epithelioid haemangioendothelioma. Arch Pathol Lab Med 1987;111:459-63.

7 Attanoos RL, Dallimore NS, Gibbs AR. Epithelioid haemangioendothelioma of the peritoneum: an unusual mimic of peritoneal mesothelioma. Histopathology 1997;30: 375-7.

8 Lin BT-Y, Colby T, Gown AM, et al. Malignant vascular tumours of the serous membranes mimicking mesothelioma. Am f Surg Pathol 1996;20:1431-9.

9 Donna A, Betta PG. Mesodermomas: a new embryological approach to primary tumours of coelomic surfaces. approach to primary tum
Histopathology 1981;5:31-44.

10 Parums DV, Cordell JL Micklem K, et al. JC 70: a new monoclonal antibody that detects endothelial associated antigen on routinely processed tissue sections. $\mathcal{F}$ Clin Pathol antigen on routine

11 Van de Rijn M, Rouse RV. CD34. A review. Appl Immunohistochem 1994;2:71-80.

12 Guarda LA, Ordonez NG, Smith JI, et al. Immunoperoxidase localisation of factor VIII in angiosarcomas. Arch Pathol Lab Med 1982;106:515-6.

3 Miettinen M, Lindenmayer AE, Chaubal A, et al. Endothelial cell markers CD31, CD34, and BNH9 antibody to $\mathrm{H}$ and Y-antigens: evaluation of their specificity and sensitivity in the diagnosis of vascular tumours and comparison with von Willebrand factor. Mod Pathol 1994;7:82-90.

14 De Young BR, Frierson HF, Ly MN, et al. CD31 immunoreactivity in carcinoma and mesotheliomas. Am $\mathcal{F}$ Clin Pathol 1998;110:374-7.

15 Davies D, Cotton R. Mica pneumoconiosis. Br f Ind Med 1983;40:22-7.

16 Vallyathan V, Bergeron W, Robichaux P, et al. Pulmonary fibrosis in an aluminium arc welder. Chest 1982;81:372-4.

17 Lanphear BP, Buncher CR. Latent period of malignant mesothelioma of occupational origin. F Occup Med 1992;7: 718-22.

18 Evans DMD, Jones-Williams W, Kung ITM. Angiosarcoma and hepatocellular carcinoma in vinyl chloride workers. Histopathology 1983;7:377-88. 